\title{
Study of personal social and psychological qualities of the bailiff service officers
}

\author{
Ekaterina Pyatkina $^{1, *}$, Elena Grinina ${ }^{1}$, Tanzilya Rudzinskaya $^{1}$ and Larisa Shipova ${ }^{1}$ \\ ${ }^{1}$ Saratov State University, Saratov, 410012, Russia
}

\begin{abstract}
The article presents the results of the study of the personal sociopsychological features in the bailiff service officers. The study involved 675 bailiff executors, 410 men $(60.7 \%)$ and 265 women (39.3\%) aged 21 to 59 years. In our study, we used a number of diagnosis tools, such as MMPI - a multifactorial questionnaire for the personality study, Brief Indicative Selection Test developed by V.N. Buzin and E.F. Wonderlic, K. Leonhard N. Shmishek diagnostic test to determine character accentuations, the projective technique "House-Tree-Person" by J. Book, as well as observations and interviews. Our study revealed mean indicators of intellectual development level related to the range of values "above average", absence of pronounced character accentuations with a tendency to hypertension and demonstrativeness and risks of a tendency to depression and rigidity. The analysis showed the relationship of certain characteristics to the subjects' age and gender. Factor analysis identified the major social and psychological personality traits of bailiffs which are the most significant for their professional activities. The study results can be used for professional psychological selection of bailiff service officers, their psychological support and the development of techniques in order to prevent burnout syndrome and professional deformation.
\end{abstract}

\section{Introduction}

Despite a fairly large number of studies devoted to the psychological characteristics of representatives of different professions with regard to gender, age and social differences, personal socio-psychological characteristics of people involved in occupations associated with a high level of professional deformation and emotional burnout are significantly underresearched.

The study of the influence of professional activity on a person is mainly associated with the concept of "professional deformation" $[1,2]$. According to many researchers in this area $[3,4]$, the main manifestation of this phenomenon is emotional burnout and/or the formation of deviant forms of behavior.

One of the most risky in terms of professional deformation is the work in executive bodies: police officers, bailiffs, correctional institution officers, etc. For example, a study by J. McDonald [5] found that ethnicity, agency size, and perceptions of fairness in promotion

\footnotetext{
*Corresponding author: cori64@mail.ru
} 
and discipline were significant correlates of burnout in police officers. At the same time, the level of education does not significantly affect professional burnout.

T. Arrows [6] attempted to establish a model of the professional quality of life among correctional officers. The author emphasizes that stress has a significant impact on their physical and mental health and in this regard considers it necessary to develop and implement preventive programs.

E. Long [7] carried out a gender-sensitive comparative study of the well-being, professional performance, and domestic responsibilities of correctional officers. Data analysis showed no significant differences in stress, burnout, overall health, pain, depression, and sleep quality. At the same time, women, compared to men, had lower well-being along with more work and the need to perform household chores. In addition, women were more likely than men to report musculoskeletal pain of various locations and significantly higher levels of fatigue.

The profession of a bailiff is associated with high physical and mental stress. It requires increased attention and actualization of cognitive abilities when working with a large volume of complex documentation, formation of communication skills and the ability to function effectively in the "person-to-person" dyad, skills of self-control and effective self-regulation and high motivation for professional activity.

A bailiff in the Russian Federation is an official in the civil service who is entrusted with the task of ensuring the established procedure for the activities of the Constitutional Court of the Russian Federation, the Supreme Court of the Russian Federation, the Supreme Arbitration Court of the Russian Federation, courts of general jurisdiction and arbitration courts, as well as for the execution of judicial acts and acts of other bodies provided for by the Federal Law "On Enforcement Proceedings". The institute of bailiffs operated in Russia until 1917 and was reintroduced in 1997.

According to the order of the FSSP of Russia (Federal Bailiff Service of Russia) dated January 17, 2020 No. 102, the main requirements that a bailiff must meet are as follows: citizenship of the Russian Federation, age from 21 to 60 years, higher education with a specialist or master's degree in the following areas "Psychological Sciences", "Economics and Management", "Jurisprudence", "Education and Pedagogical Sciences" (Order of the Federal Service of Bailiffs dated January 17, 2020 No. 102).

Bailiffs, as one of the key figures of the executive power in the Russian Federation, are endowed with broad powers, including the right to use physical force, special means and firearms. The latter determines special requirements for the psychological qualities of a bailiff, the ability to adequately and effectively analyze a stressful situation, make the right decision, mobilize one's own resources for the most optimal resolution of the problem, etc.

The above-mentioned requirements for executive authority officers predetermine the importance of psychological diagnostics of candidates for the bailiff position, as well as psychological support of professional activities in order to timely diagnose and prevent professional burnout of officers.

In modern psychology, there are only a few works that characterize the psychological aspects of bailiff service. Thus, N.V. Reutova [8] analyzed social and personal identity in the context of the socio-psychological adaptation of bailiffs; N.R. Eruslanov, R.V. Sayfullin [9] investigated the relationship of metacognitive abilities and ways of making decisions among employees of the federal bailiff service; A.A. Lukyanova [10] analyzed the psychological aspects of increasing the effectiveness of the bailiff professional activity in the aspect of interpersonal communication; A.S. Kuzmina, E.S. Arsentieva [11] describe the model of self-attitude of bailiffs, etc.

I.N. Nazarov [12] focuses on high requirements for the psychological qualities of a bailiff, such as social maturity, responsibility, organizational, communicative, ethical, emotionalvolitional qualities and intellectual abilities. The research found that most of the subjects - 
$70.4 \%$ - are nervous at work and feel stress. At the same time, only $33.6 \%$ of respondents characterize the situation at the place of service as calm. The data obtained by the study make it possible to formulate an assumption about a sufficiently high level of stress and the risk of professional deformation in bailiff service.

Analyzing the psychological characteristics of bailiffs' job, D.V. Karelin, E.I. Meshcheryakova, A.V. Larionova, P.A. Trusov [13] focus on socio-professional and personal-communicative characteristics. It was revealed that in most cases bailiffs are characterized by a competence-based type of communication, the ability to come into contact with other people, express positive assessments and feelings in relationships, demonstrate adequate reactions to the opponent's behavior, while the predominant strategy of behavior in conflict situations is compromise. Along with a fairly harmonious actual psycho-emotional status, the personal characteristics of the subjects revealed a controversial combination of a high level of ambitions and lack of self-confidence, as well as intensive activity and rapid exhaustion which indicates the risk of emotional burnout.

The high risk of professional deformation among bailiff executors is recognized by S.E. Zakharova and Z.G. Ustaev [14]. An empirical study found that male and female subjects were equally susceptible to professional burnout. At the same time, the risk of emotional burnout increases in employees with more significant professional experience ( 5 years or more). At the same time, employees with a longer work experience tend to deny the possibility of professional deformation in themselves which negatively characterizes their ability to self-reflection. The study revealed relationship between the level of emotional burnout, meaningful life attitude and coping strategies among bailiffs-executors.

The value-based orientations of bailiff executors were investigated by A.S. Kuzmina [15]. Among the most significant values are "happy family life" (9.04), "love" (7.84), "health" (8.45). The subjects noted the availability of proactive life, loyal friends and self-confidence. At the same time, they assess material security, health, a happy family life as hard-to-reach values. Such a discrepancy in assessing the significance of a value and its low availability can be considered as a significant stress factor.

The issues of psychological support for the professional and personal development of employees become relevant already at the stage of their education [16, 17]. Thus, an important area of psychological assistance is psychological correction which is reflected in the restoration and maintenance of psychological health; correction of deviant behavior and negative personality traits; the level of self-esteem, adaptation mechanisms, family and household problems, intrapersonal and interpersonal relationships; increasing the efficiency of group activities. In further professional activities, the need for psychological support does not lose its relevance, moreover, it becomes even more pronounced.

Study aims. Our study aimed to examine personal socio-psychological characteristics that influence the bailiff professional success/failure and must be taken into account in professional selection and subsequent psychological support.

\section{Materials and methods}

The empirical base of the study was 675 bailiffs. The gender distribution of the sample: 410 men $(60.7 \%)$ and 265 women (39.3\%). The age range of the subjects from 21 to 59 years old. The average age of the subjects is 36,18 years. The most common age range is 26 to 38 years old. The most frequent age is 28 years $(6.4 \%)$. Work experience range from 4 months to 17 years. According to the level of education, the subjects were distributed as follows: 565 $(83.7 \%)$ of the respondents have higher education (445 - legal, 78 - economics, 22 engineering, 15 - pedagogical and 5 - technical education), 110 (16, 3\%) - secondary education (of which 41 have legal education). 
In order to study the social and psychological characteristics, we carried out. a psychodiagnostic study of bailiff executives in the bailiff service. The following parameters were considered as socio-psychological characteristics: the age of the bailiff service officer, work experience, intellectual abilities, character accentuations, basic personality traits, emotional state and self-esteem of the subjects.

Data on the indicated parameters were obtained on the basis of the study of individual questionnaires that were filled out by the subjects, as well as a complex of psycho-diagnostic techniques: the multivariate questionnaire for personality research MMPI, the KOT test (Brief Indicative, Screening Test by V.N. Buzin and E.F. Wonderlic), K. Leonhard - N Shmishek test to determine character accentuations, the projective method "House-TreePerson" by J. Book.

\section{Results}

In order to study the socio-psychological characteristics that affect the professional success / failure of bailiffs, we analyzed the average values based on the results of the methods used in the study (Table 1). We identified indicators exceeding the thresholds of the norm while analyzing and comparing the data obtained in our study with the average normative data indicated by the authors of the above-mentioned methods.

According to the data obtained during the application of the multivariate questionnaire for the study of personality MMPI, bailiffs showed increased indicators for the following variables: D (depression) (60, $20 \pm 9.42), \mathrm{Pa}$ (rigidity) (66.14 \pm 8.71$), \mathrm{F}$ (reliability) (79.61 \pm $5.33)$ and $\mathrm{K}$ (correction) $(63.87 \pm 8.80)$ which testifies to the fact that in most professional situations bailiffs work with high internal tension against the background of low mood, with the maximum use of the individual protective resources potential. A simultaneous increase in the average indicators on the F (reliability) and $\mathrm{K}$ (correction) scales may indicate the presence of an internal conflict between the desire to meet the requirements and the desire to repress information that traumatizes the positive self-image.

The data obtained as a result of the application of the "Brief Indicative Selection Test (KOT)" by V.N. Buzin and E.F. Wonderlic revealed a fairly wide range of intellectual capabilities of the subjects: the minimum indicator is 8 points, the maximum is 50 points. The most frequent score is 39 points $(5.2 \%)$. The average value according to the KOT test is 29.45 points. For men, the average score is 29.49 points, for women -29.45 points. It should be noted that the data obtained indicate a fairly high level of mental abilities indicator (the average value according to this method refers to the range of values "above average"). Undoubtedly, the ability to analyze and quickly make the right decision is a key requirement for the selection of candidates for the position of bailiff. The data obtained do not contradict the educational level of the subjects and are the personal potential that allows bailiffs to effectively carry out their professional activities.

Table 1. Socio-psychological characteristics of the subjects (mean indicators for all scales of methods).

\begin{tabular}{|c|c|c|c|c|c|}
\hline Method & Variable & M & min & max & $\boldsymbol{\sigma}$ \\
\hline \multirow{5}{*}{} & Hs (hypochondria) & 29.86 & 22 & 57 & 7.36 \\
\cline { 2 - 6 } & D (depression) & 60.20 & 30 & 77 & 9.42 \\
\cline { 2 - 6 } & Hy (hysteria) & 55.23 & 24 & 80 & 9.30 \\
\cline { 2 - 6 } & Pd (impulsivity) & 43.88 & 15 & 70 & 7.86 \\
\cline { 2 - 6 } & Mf (masculinity/ femininity ) & 57.49 & 30 & 80 & 11.04 \\
\cline { 2 - 6 } & Pa ( rigidity) & 66.14 & 3 & 82 & 8.71 \\
\cline { 2 - 6 } & $\mathrm{Pt}$ (psychostenia) & 20.76 & 4 & 73 & 8.66 \\
\cline { 2 - 6 } & $\mathrm{Sc}$ ( schizoidness) & 33.24 & 10 & 64 & 7.69 \\
\hline
\end{tabular}




\begin{tabular}{|c|c|c|c|c|c|}
\hline \multirow{4}{*}{} & Ma ( hypomania) & 49.25 & 25 & 83 & 8.66 \\
\cline { 2 - 6 } & Si ( introversion) & 48.10 & 35 & 71 & 5.70 \\
\cline { 2 - 6 } & L (lie) & 51.70 & 36 & 83 & 9.06 \\
\cline { 2 - 6 } & F ( reliability) & 79.61 & 40 & 80 & 5.33 \\
\cline { 2 - 6 } & K (correction) & 63.87 & 36 & 84 & 8.80 \\
\hline KOT & 29. & 8 & 50 & 9.52 \\
\hline Shmishek test & General level of intellectual abilities & 16.48 & 3 & 24 & 16.01 \\
\cline { 2 - 6 } & Hypertension & 12.27 & 0 & 22 & 3.37 \\
\cline { 2 - 6 } & Sticking & 9.06 & 0 & 22 & 4.52 \\
\cline { 2 - 6 } & Pedantry & 13.18 & 0 & 24 & 5.31 \\
\cline { 2 - 6 } & Emotiveness & 6.28 & 0 & 24 & 4.98 \\
\cline { 2 - 6 } & Anxiety & 9.39 & 0 & 21 & 3.22 \\
\cline { 2 - 6 } & Cycloidity & 5.00 & 0 & 18 & 3.32 \\
\cline { 2 - 6 } & Excitability & 9.86 & 0 & 21 & 3.58 \\
\cline { 2 - 6 } & Dysthymia & 10.35 & 2 & 24 & 3.45 \\
\cline { 2 - 6 } & Demonstrativeness & 0 & 24 & 4.24 \\
\hline
\end{tabular}

Average values of the variables obtained on the basis of the K. Leonhard- N. Shmishek test did not significantly exceed the standard indicators. There was a slight increase in indicators on the scale "Hypertension" $(16.48 \pm 16.01)$ and on the scale "Demonstrativeness" $(14.35 \pm 3.45)$. But these average values refer to the range of the average severity of the property, therefore, it would be unjustified to talk about these character traits as typical for the personality of bailiffs as a whole. If we consider the results of individual respondents, then an increase in indicators for the parameter "Hypertension" was encountered quite often in the group of subjects. Very low indicators for such variables as "Anxiety", "Excitability" create a double impression: on the one hand, low indicators indicate a favorable situation in the professional and personal spheres of the subjects; on the other hand, the analysis of the data of the projective method "House-Tree-Person" by J. Book in $25 \%$ of the subjects testified to the opposite trend.

According to the data obtained on the basis of the Spearman correlation analysis presented in Table 2 we revealed a direct relationship between the parameter "Age" and the variables "Hypochondria" ( $\mathrm{r}=0.43)$, "Depression" ( $\mathrm{r}=0.43)$, "Schizoidness" $(\mathrm{r}=0.48)$, "Lie" $(\mathrm{r}=$ $0.4)$, "Sticking" $(\mathrm{r}=0.46)$, and "Cycloidity" $(\mathrm{r}=0.47)$. The parameter "Gender" (in this case, we are talking about the female gender of the subjects) positively correlates with the variables "Hysteria" $(\mathrm{r}=0.49)$ and "Hypertension" $(\mathrm{r}=0.36)$. Also, we found positive relationships between the variables: "Hypochondria" and "Lie" ( $\mathrm{r}=0.43)$; "Depression" and "Sticking" ( $\mathrm{r}$ $=0.44)$; "Rigidity" and "Pedantry" $(\mathrm{r}=0.38)$, "Emotiveness" $(\mathrm{r}=0.46)$; "Intellectual abilities" and "Correction" $(\mathrm{r}=0.44)$, "Exaltation" $(\mathrm{r}=0.41)$. "Emotiveness" positively correlates with rigidity $(r=0.47)$, "dysthymia" $(r=0.33)$ and demonstrativeness $(r=0.34)$.

Table 2. The results of the relationship between socio-professional and psychological characteristics $(\mathrm{p} \leq 0.01)$.

\begin{tabular}{|c|c|c|c|c|c|c|c|c|c|c|c|}
\hline Variable & $\ddot{0}$ & ن̈ & 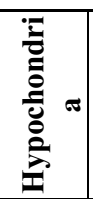 & 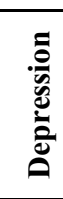 & 竞 & 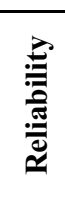 & نِّ & 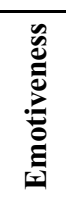 & 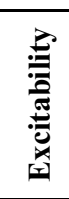 & 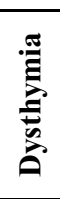 & 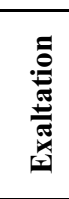 \\
\hline $\begin{array}{l}\text { Intellectusl } \\
\text { abilities }\end{array}$ & - & - & - & - & - & - & 0.44 & - & - & - & 0.41 \\
\hline $\begin{array}{l}\text { Hs } \\
\text { (hypochondria) } \\
\text { (hypochondria) }\end{array}$ & 0.43 & - & 1 & - & - & - & - & - & - & - & - \\
\hline
\end{tabular}




\begin{tabular}{|l|l|l|l|l|l|l|l|l|l|l|l|}
\hline D (depression) & 0.43 & - & - & 1 & - & - & - & - & - & - & - \\
\hline Hy (hysteria) & - & 0.49 & - & - & - & - & - & - & 0.39 & - & - \\
\hline Pa (rigidity) & - & - & - & - & 1 & - & - & 0.47 & - & - & 0.38 \\
\hline Sc(schizoidness) & 0.48 & - & - & - & - & - & - & - & - & - & - \\
\hline L (Lie) & 0.4 & - & 0.43 & - & - & - & - & - & - & - & - \\
\hline Hypertension & - & 0.36 & - & - & - & - & 0.33 & - & 0.43 & - & - \\
\hline Sticking & 0.46 & - & - & 0.44 & - & 0.43 & - & - & - & 0.31 & - \\
\hline Pedantry & 0.34 & - & - & - & 0.38 & - & - & - & - & - & - \\
\hline Emotiveness & - & - & - & - & 0.46 & 0.38 & - & 1 & - & 0.42 & - \\
\hline Cycloidity & 0.47 & - & - & - & - & - & - & - & - & - & - \\
\hline Dysthymia & - & - & - & - & - & - & - & 0.42 & 0.33 & 1 & - \\
\hline Demostrativeness & - & - & - & - & - & - & - & 0.43 & 0.39 & 0.34 & - \\
\hline
\end{tabular}

To identify the main socio-psychological personality traits of bailiffs, we carried out a factor analysis of the data using the SPSS package from Varimax rotation method. All variables were distributed according to 6 factors (Table 3).

Table 3. Factor analysis results, rotated component matrix (Varimax rotation method).

\begin{tabular}{|c|c|c|c|c|c|c|}
\hline Variables & 1 & 2 & 3 & 4 & 5 & 6 \\
\hline Excitability & 0.681 & & & & & \\
\hline Cycloidity & 0.645 & & & & & \\
\hline Anxiety & 0.575 & & & 0.441 & & \\
\hline Emotiveness & 0.550 & & & 0.509 & & \\
\hline Sticking & 0.530 & & & & & \\
\hline L (lie) & -0.521 & & 0.345 & & & 0.382 \\
\hline Pedantry & 0.514 & & & & & 0.388 \\
\hline Exaltation & 0.450 & & & & & \\
\hline Sc (schizoidness) & & 0.811 & & & & \\
\hline Pt (psychastenia) & 0.474 & 0.709 & & & & \\
\hline F (reliabilty) & & 0.625 & & & & \\
\hline Hs (hypochondria) & & 0.545 & 0.437 & & & \\
\hline Hy (hysteria) & & & 0.824 & & & \\
\hline $\mathrm{Pa}$ (rigidity) & & & 0.705 & & & \\
\hline Pd (impulsivity) & & 0.347 & 0.600 & & & \\
\hline $\mathrm{K}$ (correction) & -0.502 & -0.467 & 0.562 & & & \\
\hline $\mathrm{D}$ (depression) & & & 0.531 & & -0.452 & 0.317 \\
\hline Gender & & & & 0.850 & & \\
\hline Mf & & & & 0.777 & & \\
\hline Age & & & & -0.552 & & \\
\hline $\mathrm{Si}$ (introversion) & & 0.432 & & & -0.665 & \\
\hline Demonstrativeness & & & & & 0.659 & \\
\hline Hypertension & & & & & 0.629 & \\
\hline Ma (hypomania) & & 0.539 & & & 0.598 & \\
\hline Intellectual abilities & & & & & & -0.619 \\
\hline Dysthymia & & & & & & 0.563 \\
\hline
\end{tabular}

\section{Discussion}

The first factor consisted of the following variables: "Excitability", "Cycloidity", "Anxiety", "Emotiveness", "Sticking", "Lies", "Pedantry" and "Exaltation". Taking into account the characteristics of the variables and the identified relationships between the variables, this factor was designated as "Emotional instability, vividness of emotional experiences with 
negative fixation." The second factor "Avoiding interaction in stressful situations due to emotional exhaustion" combined 8 variables. The third factor was defined as "Protective demonstrative emotionality" and included the following scales: "Lies", "Hypochondria", "Hysteria", "Rigidity", "Impulsivity", "Correction", "Depression". The fourth factor was formed by 5 parameters, the content of which made it possible to designate it as "Difficulties of adaptation in professional activity associated with internal conflicts." The fifth factor was named "Harmonious Activity". The sixth factor, based on the variables included in it, is designated by us as "Stereotype and limitation of the behavioral repertoire."

\section{Conclusions}

The results of the study allow us to state the absence of pronounced personal deformities in the bailiff officers. The study also revealed contradictory tendencies manifested in a bias to hypertension and demonstrativeness, together with an exceedance of indicators on the "depression" and "rigidity" scales, which may indicate the presence of an intrapersonal conflict. Indicators of the intellectual level of the subjects are mainly in the range exceeding the average values. A number of socio-psychological characteristics mostly of an emotional character are proved to be associated with the parameters of age and gender. The study of the socio-psychological personality traits of the bailiff service officers is of great importance for the psychological selection of personnel and identification of the personality traits significant for the bailiffs' professional duties. It is instrumental for the diagnosis of the personal potential of officers, prevention of emotional burnout and professional deformation.

\section{References}

1. E.F. Zeer, Psychology of professions (Academic Project, Moscow, 2003)

2. E.A. Klimov, Introduction to the psychology of labor (Moscow State University Academy, Moscow, 2004)

3. V.E. Orel, Psychological journal 1(22), 9-101 (2001)

4. A.G. Karayani, I.V. Syromyatnikov, Applied military psychology (Peter, Moscow, 2006)

5. J. McDonald, Correlates to Police and Correctional Officer Burnout: An Exploratory Study, dissertation (University of Central Florida Orlando, Spring Term, 2012)

6. T. Arrows, Validation of the Professional Quality of Life Model Among Correctional Officers (Liberty University, 2018)

7. E. Long, Gender Differences in Correctional Supervisor Wellbeing, Work, and Home Demands. Honors Scholar heses, http://www. opencommons.uconn.edu/srhonors_theses/703

8. N.V. Reutova, The relationship of social and personal identity as a factor in the sociopsychological adaptation of bailiffs: author. dis....Cand. psychol. sciences (M., 2013)

9. N.R. Eruslanova, R.V. Saifullin, Bulletin of the Bashkir University 2(23), 571-575 (2018)

10. A.A. Lukyanova, Jurisprudence in theory and practice: topical issues and modern aspects. Collection of articles of the III International scientific-practical conference, 165-167 (2020)

11. A.S. Kuzmina, E.S. Arsentieva, Collection of articles of the International Scientific and Practical Conference, 725-728 (2017)

12. I.N. Nazarov, Bulletin of Stavropol State University 55, 97-100 (2008) 
13. D.V. Karelin, E.I. Meshcheryakova, A.V. Larionova, P.A. Trusov, Bulletin of Tomsk State University 410, 172-178 (2016)

14. S.E. Zakharova, Z.G. Ustaev, Akmeologiya 1, 124-127 (2017)

15. A.S. Kuzmina, Bulletin of the Altai State University 2-2(82), 33-37 (2014)

16. O.A. Ulyanina, Psychological science and education 6(24), 28-37 (2019)

17. Y.I. Likhtman, L.V. Shipova, Education in the modern world, 370-378 (2017) 